\title{
Analysis of Charge Redistribution During Self-discharge of Double-Layer Supercapacitors
}

\author{
CHENGLONG HAO,${ }^{1}$ XIAOFENG WANG,${ }^{1,2}$ YAJIANG YIN, ${ }^{1}$ \\ and ZHENG YOU ${ }^{1}$
}

1.-Department of Precision Instruments, Tsinghua University, No. 1 Tsinghuayuan, Haidian District, Beijing, People's Republic of China. 2.-e-mail: xfw@tsinghua.edu.cn

\begin{abstract}
Self-discharge is an important factor that severely affects the performance of double-layer supercapacitors. This paper studies the self-discharge behavior of double-layer supercapacitors with experimental and modeling methods. The movement of ions, side-reactions, and instability of the double layer are taken into consideration. The influence of various factors, such as the initial voltage, charge duration, short-term history, and current, on the self-discharge is simulated, showing good agreement with experimental data. The simulation of the ion distribution also gives a detailed explanation of the mechanism of self-discharge and verifies the interpretation of the relaxation process proposed in a recent study. It further clarifies the key role of the charging/discharging current in influencing charge redistribution during self-discharge, which was neglected in previous studies. The results show that the relaxation period during which the supercapacitor loses energy very quickly is due to the unbalanced distribution of ions, and it could be avoided by further charging or by applying a small charging current.
\end{abstract}

Key words: Double-layer capacitor, modeling, self-discharge, relaxation period, charge redistribution

\section{List of symbols}

$C_{\mathrm{dl}} \quad$ Double-layer capacitance $(\mathrm{F} / \mathrm{m})$

$c_{1} \quad$ Electrolyte concentration $(\mathrm{mol} / \mathrm{L})$

$D_{1, \text { eff }} \quad$ Effective diffusion coefficient of electrolyte

$D_{1} \quad$ Diffusion coefficient of electrolyte

$F \quad$ Faraday's constant, 96,484 C/equiv

$i_{0} \quad$ Exchange current density $\left(\mathrm{A} / \mathrm{m}^{3}\right)$

$I_{\text {cell }}$ Total current density $\left(\mathrm{A} / \mathrm{m}^{2}\right)$

$i_{1} \quad$ Current density in electrolyte phase $\left(\mathrm{A} / \mathrm{m}^{2}\right)$

$i_{\mathrm{s}} \quad$ Current density in solid phase $\left(\mathrm{A} / \mathrm{m}^{2}\right)$

$L_{+} \quad$ Thickness of positive electrode $(\mu \mathrm{m})$

$L_{\mathrm{e}} \quad$ Thickness of separator $(\mu \mathrm{m})$

$L_{-} \quad$ Thickness of negative electrode $(\mu \mathrm{m})$

$R \quad$ Universal gas constant, $8.314 \mathrm{~J} /(\mathrm{mol} \mathrm{K})$

$S_{\mathrm{f}} \quad$ Specific surface area for side-reactions per unit electrode volume $\left(\mathrm{m}^{-1}\right)$

$S_{\mathrm{d}} \quad$ Specific surface area for double-layer capacitance per unit electrode volume $\left(\mathrm{m}^{-1}\right)$

$T \quad$ Absolute temperature (K)

$t \quad$ Time (s)

$t_{+} \quad$ Transport number

(Received October 21, 2015; accepted January 16, 2016; published online February 8, 2016)
$U_{1} \quad$ Equilibrium potential (V)

$\alpha_{a} \quad$ Anodic transfer coefficient of faradaic reaction

$\alpha_{c} \quad$ Cathodic transfer coefficient of faradaic reaction

$\varepsilon_{1} \quad$ Volume fraction of electrolyte phase

$\varepsilon_{\mathrm{s}} \quad$ Volume fraction of solid phase

$\sigma_{1, \text { eff }} \quad$ Effective conductivity in electrolyte phase (S/ $\mathrm{m})$

$\sigma_{1} \quad$ Conductivity in electrolyte phase $(\mathrm{S} / \mathrm{m})$

$\sigma_{\mathrm{s}, \text { eff }} \quad$ Effective conductivity in solid phase $(\mathrm{S} / \mathrm{m})$

$\sigma_{\mathrm{s}} \quad$ Conductivity in solid phase $(\mathrm{S} / \mathrm{m})$

$\phi_{1} \quad$ Potential in electrolyte phase (V)

$\phi_{\mathrm{s}} \quad$ Potential in solid phase (V)

\section{INTRODUCTION}

Electrochemical double-layer capacitors are useful storage devices. They have very distinctive characteristics, such as high power density and large cycle time, ${ }^{1-3}$ which make them more 
suitable than batteries in various conditions. However, one of the drawbacks of supercapacitors is their high self-discharge rate, which is much more pronounced than in batteries. ${ }^{4}$

To date, only a few studies discussing the mechanism behind the self-discharge phenomenon have been published. Conway et al. ${ }^{5}$ gave a general description of self-discharge mechanisms and provided three possible routes: electrolyte decomposition, impurities, and internal ohmic leakage pathways. However, Levie et al. believed ${ }^{6}$ that Conway's model overlooked charge redistribution, which is a result of an uneven charging process across the electrode. Ricketts and Ton-That ${ }^{7}$ divided the self-discharge into two stages: the first is a diffusion process during the first $1 \mathrm{~h}$ or $2 \mathrm{~h}$ when more energy is lost, and the second is a slower leakage process. However, they did not discover the nature of the reactions and guessed that the presence of water in the organic electrolyte might be a factor. Furthermore, Black and Andreas ${ }^{8}$ demonstrated the effect of charge redistribution in the selfdischarge process. More recently, Kowal et al. ${ }^{9}$ revealed the role of the relaxation period in selfdischarge, as inferred from their experiments, which also showed that the self-discharge rate depends on various parameters such as the initial voltage, temperature, charge duration, and shortterm history. To account for the relaxation effect in self-discharge, Kaus et al. ${ }^{10}$ proposed an electrical model which was able to predict the effects of these parameters. However, both of them overlooked the important role of current in elaborating the mechanism of self-discharge.

This paper proposes a dynamic mathematical model simulating the self-discharge behavior of supercapacitors. It considers the common factors used by previous researchers. ${ }^{6-8}$ The novelty of the model is that it simulates the movement of charges in the electrolyte as well as in the electronic double layer, enabling simulation of the self-discharge mechanism. We repeated some of the experiments from Kowal et al.'s study ${ }^{9}$ and further investigated the effect of current. Through simulation of the movement of ions between the electrode and electrolyte as well as across the electrolyte, we finally demonstrate their conclusion about the effect of charge redistribution on self-discharge. Furthermore, the simulation and experimental data also show that a critical factor-the charging/discharging current-actually plays a determining role in charge redistribution during self-discharge, which was neglected by previous studies.

\section{EXPERIMENTAL PROCEDURES}

We repeated some of the experiments from Kowal et al.'s study ${ }^{9}$ and further investigated the effect of current. A $360 \mathrm{~F}$ commercial carbon-based supercapacitor with organic electrolyte was used for all the experiments presented in this paper. The activated carbon (AC) used in the supercapacitor has Brunauer-Emmett-Teller (BET) specific surface area of $1453 \mathrm{~m}^{2} / \mathrm{g}$. The electrolyte was acetonitrile solution of quaternary ammonium salt with conductivity of $0.94 \mathrm{~S} / \mathrm{m}$. All experiments were performed using a PARSTAT 2273 (0 A to $2 \mathrm{~A}$ ) at room temperature.

\section{Effect of Initial Voltage}

As shown in Fig. 1, the supercapacitor was charged to different voltages $(1.5 \mathrm{~V}, 2.0 \mathrm{~V}, 2.4 \mathrm{~V}$, and $2.7 \mathrm{~V}$ ) at current of $250 \mathrm{~mA}$ and then placed to display the self-discharge phenomenon. The results show that the voltage decayed faster for higher initial voltage. Moreover, the relaxation period tended to last $10 \mathrm{~h}$ or even longer at $2.7 \mathrm{~V}$, while it lasted for no more than $2 \mathrm{~h}$ at $1.5 \mathrm{~V}$.

\section{Effect of Charge Duration}

Figure 2 shows the dependence of the self-discharge on the charge duration. The supercapacitor was further charged for $12 \mathrm{~h}, 2 \mathrm{~h}$, and $0 \mathrm{~h}$, respectively, after being charged to $2.7 \mathrm{~V}$ at current of $250 \mathrm{~mA}$. The results show that such further charging reduced the rate of self-discharge during the relaxation period. However, periods after the relaxation were almost unaffected: after about $25 \mathrm{~h}$, the rate of self-discharge became the same.

\section{Effect of Current}

The impact of current on self-discharge has rarely been studied. So, in this experiment, the supercapacitor was charged to $2.7 \mathrm{~V}$ at $62.5 \mathrm{~mA}, 125 \mathrm{~mA}$, $250 \mathrm{~mA}, 500 \mathrm{~mA}$, and $1000 \mathrm{~mA}$. The effect on selfdischarge is displayed in Fig. 3. When the current was lower than $250 \mathrm{~mA}$, increasing the current caused a larger voltage decay during the relaxation period. However, when the current exceeded $250 \mathrm{~mA}$, the voltage decay became smaller due to

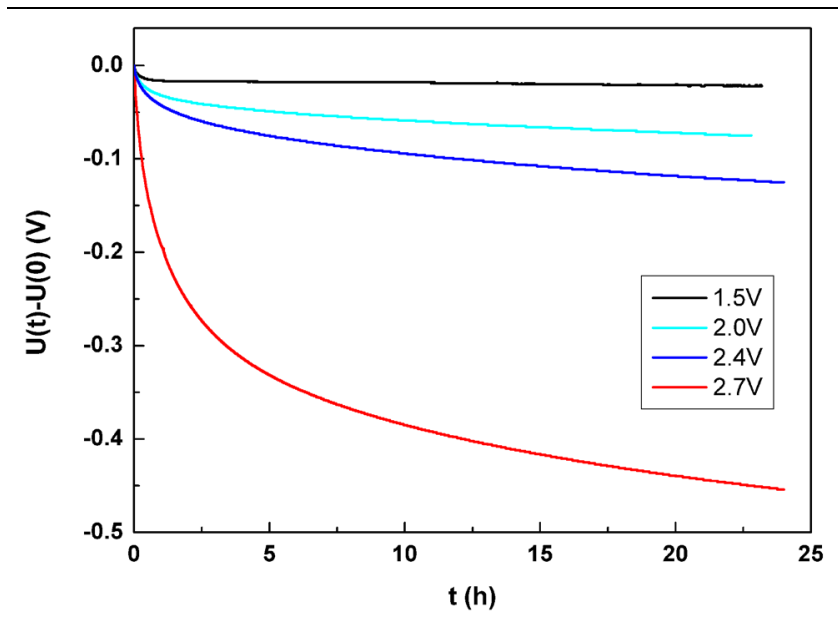

Fig. 1. Voltage decay of supercapacitor in self-discharge after charging to $1.5 \mathrm{~V}, 2.0 \mathrm{~V}, 2.4 \mathrm{~V}$, and $2.7 \mathrm{~V}$ at current of $250 \mathrm{~mA}$ (Color figure online). 


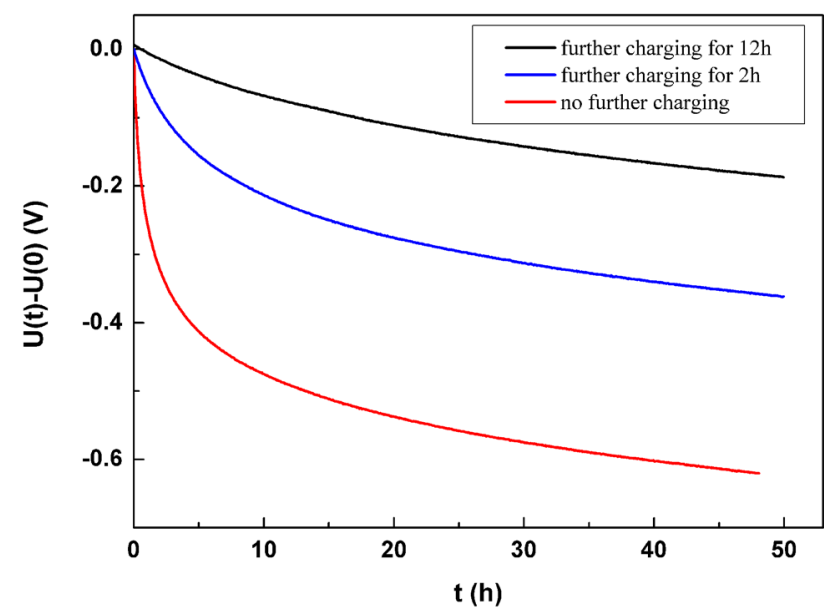

Fig. 2. Voltage decay of supercapacitor for different charge durations in self-discharge after charging to $2.7 \mathrm{~V}$ at current of $250 \mathrm{~mA}$ (Color figure online).

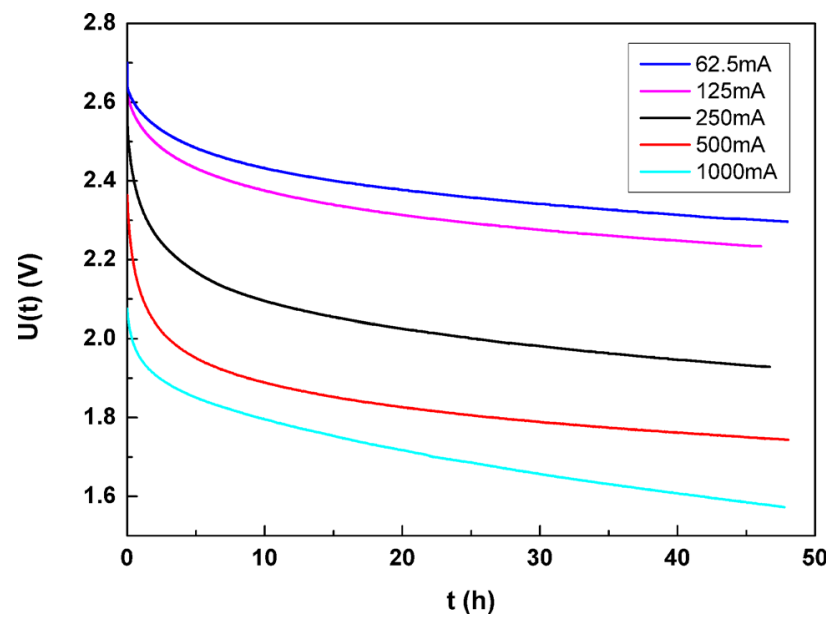

Fig. 3. Voltage decay of supercapacitor after charging to $2.7 \mathrm{~V}$ at $62.5 \mathrm{~mA}, 125 \mathrm{~mA}, 250 \mathrm{~mA}, 500 \mathrm{~mA}$, and $1000 \mathrm{~mA}$ (Color figure online).

the lower initial voltage. Figure 3 shows that in fact there was a combined effect of current and initial voltage.

\section{Effect of Short-Term History and Current}

Figure 4 shows the influence of the short-term history on the self-discharge. Two conditions were considered: firstly, the supercapacitor was charged to $2.1 \mathrm{~V}$ at $250 \mathrm{~mA}$ and further charged for $12 \mathrm{~h}$, then charged at $50 \mathrm{~mA} / 2.4 \mathrm{~V}$ without further charging; secondly, the supercapacitor was charged to $2.7 \mathrm{~V}$ at $250 \mathrm{~mA}$ and further changed for $12 \mathrm{~h}$, then discharged at $50 \mathrm{~mA}$ to $2.4 \mathrm{~V}$ without further charging. The results show that the self-discharge was different under the different conditions. The supercapacitor underwent a large voltage decay after a short charging process, whereas its voltage underwent a small increase after a short-term discharging process. Then, the impact of current

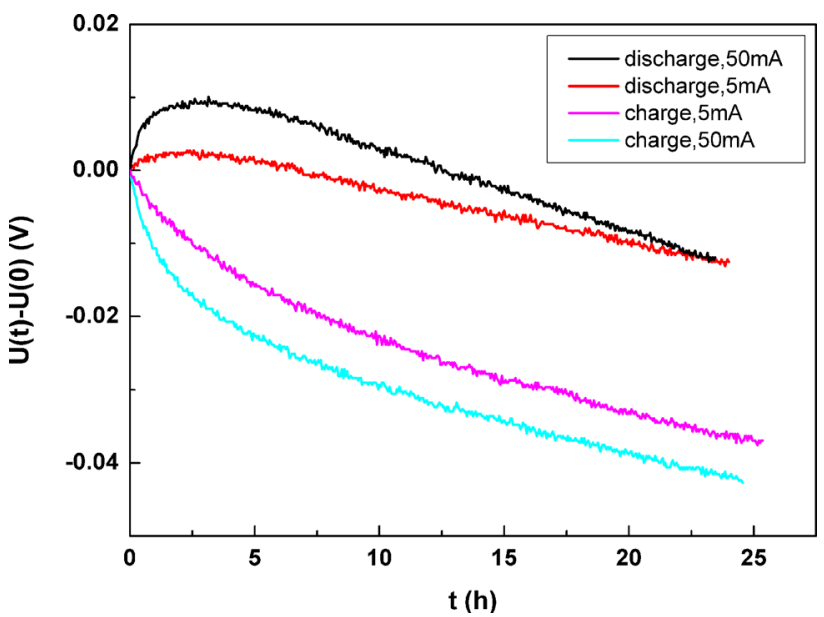

Fig. 4. Voltage decay of supercapacitor after short-term histories performed with different currents (charging to $2.4 \mathrm{~V}$ after charging for $12 \mathrm{~h}$ to $2.1 \mathrm{~V}$, or discharging to $2.4 \mathrm{~V}$ after charging for $12 \mathrm{~h}$ to $2.7 \mathrm{~V}$, at $50 \mathrm{~mA}$ and $5 \mathrm{~mA}$, respectively) (Color figure online).

on the short-term history effect was investigated by decreasing the charging/discharging current from $50 \mathrm{~mA}$ to $5 \mathrm{~mA}$. As shown in Fig. 4, the voltage variations in the relaxation period became much smaller under a small current.

\section{MODEL DESCRIPTION}

To investigate the self-discharge behavior of double-layer supercapacitors, we propose a dynamic mathematical model. In contrast to equivalent circuit models, ${ }^{10}$ this model uses parameters with physical meanings and describes the real physical phenomenon. Many models have been developed to describe the behavior of double-layer capacitors. Posey and Morozumi developed a model to simulate the potentiostatic and galvanostatic charging of double-layer capacitors with porous electrodes. ${ }^{11}$ Johnson and Newman's model ${ }^{12}$ described the ionic absorption process in the double layers. Pillay and Newman ${ }^{13}$ went on to study the influence of sidereactions on the capacitor's performance. More influential variables were studied by Srinivasan and Weidner, ${ }^{14}$ including ionic and electronic resistance, in the design of supercapacitors. Unfortunately, none of these models can provide a complete description of the self-discharge behavior, although they provide a theoretical basis. Besides, we recently developed a model of an asymmetric supercapacitor and studied the relaxation process during discharge. ${ }^{15}$

Figure 5 presents a schematic diagram of a typical double-layer supercapacitor, consisting of two identical porous electrodes and a separator. The electrode is composed of AC and acetylene black $(\mathrm{AB})$. As electrolyte, acetonitrile solution of quaternary ammonium salt fills the pores in the electrode and separator. During charge/discharge, the doublelayer reaction takes place between the interface of the solid phase and the electrolyte phase inside the electrode. 


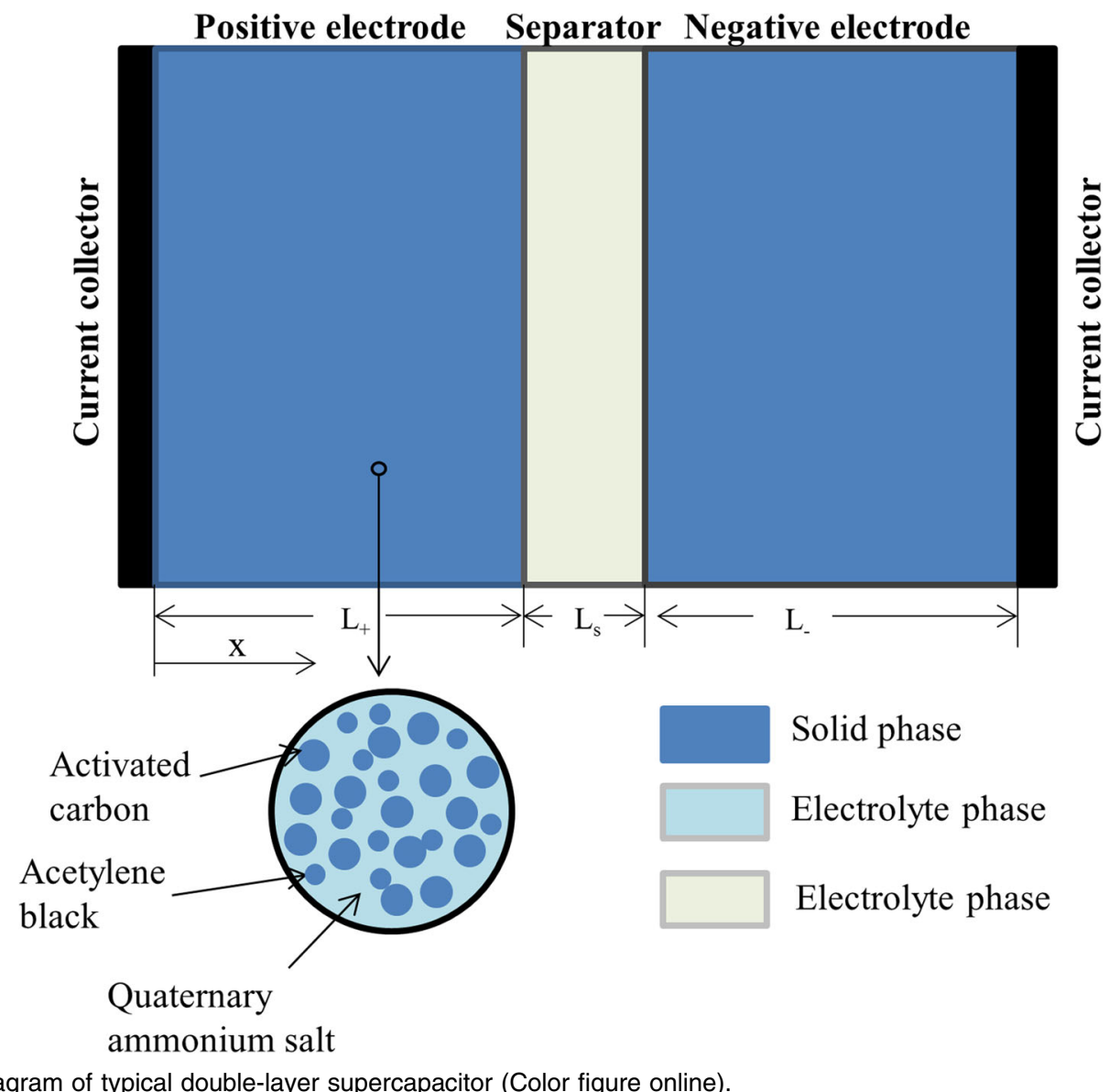

Fig. 5. Schematic diagram of typical double-layer supercapacitor (Color figure online).

A one-dimensional mathematical model is developed for the double-layer supercapacitor to describe its self-discharge behavior. The diffusion coefficient in the solid and solution phase and the transport number are assumed to be independent of the electrolyte concentration. All thermal effects are neglected, but the side-reactions concerning impurities and electrolyte decomposition are taken into consideration.

Considering the porous characteristic of the electrode, the conductivity and diffusion coefficient should be modified in the electrode area ${ }^{16}$ :

$$
\begin{gathered}
D_{\mathrm{l}, \mathrm{eff}}=\varepsilon_{1}^{1.5} D_{1}, \\
\sigma_{\mathrm{l}, \mathrm{eff}}=\varepsilon_{1}^{1.5} \sigma_{\mathrm{l}}, \\
\sigma_{\mathrm{s}, \mathrm{eff}}=\varepsilon_{\mathrm{s}}^{1.5} \sigma_{\mathrm{s}},
\end{gathered}
$$

where $D_{\mathrm{l}, \mathrm{eff}}, \sigma_{\mathrm{l}, \mathrm{eff}}$, and $\sigma_{\mathrm{s}, \mathrm{eff}}$ are the effective diffusion coefficient of the electrolyte, the effective conductivity in the electrolyte phase, and the effective conductivity in the solid phase, respectively. Their original values are $D_{1}, \sigma_{1}$, and $\sigma_{\mathrm{s}} . \varepsilon_{1}$ is the volume fraction of the electrolyte phase, and $\varepsilon_{\mathrm{s}}$ is the volume fraction of the solid phase.

At any given time, when the total current density for charging is $I_{\text {cell }}$, then for every position in the model, conservation of charge leads to

$$
I_{\text {cell }}=i_{\mathrm{s}}+i_{1}, \quad 0=\frac{\partial i_{\mathrm{s}}}{\partial x}+\frac{\partial i_{1}}{\partial x}
$$

where $i_{\mathrm{s}}$ represents the current density in the solid phase, and $i_{1}$ is the current density in the electrolyte phase. As the capacitor charges, the current is transferred from the solid phase to the electrolyte phase continuously in the positive electrode, with $i_{\mathrm{S}}$ decreasing and $i_{1}$ increasing. In the negative electrode, the current is gradually transferred back from the electrolyte phase, with $i_{\mathrm{s}}$ increasing and $i_{1}$ decreasing. However, it travels only in the electrolyte phase in the field of the separator because no electrons are allowed to move in this area. The transfer of the current is powered mainly by the double-layer charge but is influenced by the side-reactions due to impurities and electrolyte decomposition.

$$
\frac{\partial i_{1}}{\partial x}=S_{\mathrm{d}} C_{\mathrm{dl}} \frac{\partial\left(\phi_{\mathrm{s}}-\phi_{\mathrm{l}}\right)}{\partial t}+S_{\mathrm{f}} j_{\mathrm{f}},
$$

where $S_{\mathrm{d}}$ is the specific surface area for the doublelayer capacitance per unit electrode volume. $C_{\mathrm{dl}}$ represents the double-layer capacitance. $\phi_{\mathrm{s}}$ and $\phi_{\mathrm{l}}$ are the potential in the solid phase and in the electrolyte phase, respectively. $S_{f}$ is the specific surface area for the side-reactions, and $j_{\mathrm{f}}$ is the corresponding transfer current density. 
Side-reactions play a very important part in accounting for the mechanism of self-discharge. They are assumed to occur only in a small area of the total electrode area and only when the capacitor voltage reaches a threshold value, $E_{1}$; For example, the decomposition voltage of water is $1.3 \mathrm{~V}$. The instability of the double layers should also be taken into account. They are assumed to be more unstable for greater capacitor voltage. In a similar way, only a small part of the double layers tend to be broken at the same time. The escape of ions tends to decrease the capacitor voltage to another value, $E_{2}$. Both side-reactions and the instability of the double layer are hard to measure. Therefore, we put them together and use a single transfer current $j_{\mathrm{f}}$ to describe their combined contribution. This can be described in kinetic form using the Butler-Volmer equation:

$$
\begin{aligned}
j_{\mathrm{f}}= & i_{0}\left\{\exp \left[\alpha_{\mathrm{a}} \frac{F}{R T}\left(\phi_{\mathrm{s}}-\phi_{\mathrm{l}}-U_{1}\right)\right]\right. \\
& \left.-\exp \left[-\alpha_{\mathrm{c}} \frac{F}{\mathrm{RT}}\left(\phi_{\mathrm{s}}-\phi_{\mathrm{l}}-U_{1}\right)\right]\right\},
\end{aligned}
$$

where $\alpha_{\mathrm{a}}$ and $\alpha_{\mathrm{c}}$ are the anodic and cathodic transfer coefficients of the faradaic reaction, $F$ is Faraday's constant, $R$ is the universal gas constant, $T$ is the absolute temperature, $i_{0}$ is the exchange current density, and $U_{1}$ is the equilibrium potential, which stands for the combined effect of the side-reactions and the instability of the double layer. $U_{1}$ is the "driving force," which provides a tendency for the voltage to drop, referred to in Conway's study. ${ }^{5} U_{1}$ is not fixed but is expected to vary during the selfdischarge process. Because there are not enough physical property parameters to determine the equilibrium, it was only evaluated approximately according to the experimental data. law

In the solid phase, $\phi_{\mathrm{s}}$ is correlated to $i_{\mathrm{s}}$ by Ohm's

$$
i_{\mathrm{s}}=-\sigma_{\mathrm{s}, \mathrm{eff}} \frac{\partial \phi_{\mathrm{s}}}{\partial x}
$$

In the electrolyte phase, however, Ohm's law is modified to consider the porosity of the electrode $\mathrm{e}^{17}$

$$
i_{1}=-\sigma_{1, \mathrm{eff}} \frac{\partial \phi_{1}}{\partial x}-\frac{2 \sigma_{\mathrm{l}, \mathrm{eff}} R T}{F}\left(1-t_{+}\right) \frac{\partial\left(\ln c_{1}\right)}{\partial x},
$$

where $t_{+}$is the transport number. The concentration of the electrolyte $c_{1}$ is also correlated to the faradaic redox reaction and the double-layer reaction through a material balance on the electrolyte using concentrated solution theory ${ }^{16}$ :

$$
\varepsilon_{1} \frac{\partial c_{1}}{\partial t}+\nabla \cdot\left(-D_{1, \mathrm{eff}} \nabla c_{1}+\frac{i_{1} t_{+}}{F}\right)=\frac{1}{F} \frac{\partial i_{1}}{\partial x} .
$$

In the separator, porous electrode theory is not applicable. Equations 6 and 7 can be simplified to

$$
\begin{gathered}
i_{1}=-\sigma_{1, \mathrm{eff}} \frac{\partial \phi_{1}}{\partial x} \\
\frac{\partial c_{1}}{\partial t}+\nabla \cdot\left(-D_{1} \nabla c_{1}+\frac{i_{1} t_{+}}{F}\right)=0
\end{gathered}
$$

The boundary conditions of the model include: At $x=0$ :

$$
\frac{\partial c_{1}}{\partial x}=0, \quad i_{1}=0, \quad I_{\text {cell }}=i_{\mathrm{s}}
$$

$$
\begin{aligned}
& \text { At } x=L_{+}=L_{+}+L_{\mathrm{s}} \text { : } \\
& \qquad i_{\mathrm{s}}=0, \quad \frac{\partial i_{1}}{\partial x}=0 .
\end{aligned}
$$

$$
\begin{aligned}
& \text { At } x=L_{+}+L_{\mathrm{s}}+L_{-}: \\
& \quad \frac{\partial c_{1}}{\partial x}=0, \quad i_{1}=0, \quad I_{\text {cell }}=i_{\mathrm{s}}, \quad \phi_{\mathrm{s}}=0 .
\end{aligned}
$$

The initial conditions are:

At $t=0$ :

$$
c_{1}=c_{0},\left.\quad \phi_{\mathrm{s}}\right|_{x=0}=0,
$$

where $c_{0}$ is the initial concentration of the electrolyte.

The model equations include the double-layer process, the side-reactions, the instability of the double layer, the porosity characteristic of the electrodes, and the ion transport inside the porous electrode. Because the variables are coupled with each other, they can only be solved simultaneously. The equations of the model were solved using COMSOL Multiphysics software using the model parameters listed in Table I.

\section{RESULTS AND DISCUSSION}

\section{Movement of Ions During the Charge/Self- discharge Process}

The ion distributions of the positive charges in the electrolyte were simulated during charging, as shown in Fig. 6. Numerous double layers form at the interface between the solid phase and the electrolyte phase of the porous electrode. In the electrolyte phase of the negative electrode, positive charges begin to decrease as they are absorbed by the opposite charges in the solid phase to form the double layer. The reaction rate is not the same in different areas of the electrode. The transport of ions falls behind and cannot catch up with the absorption of ions, which leads to an unbalanced distribution of negative ions along the capacitor, as seen in Fig. 6. There are only a few positive ions left in the electrolyte phase of the negative electrode because most have been absorbed to form the double 
Table I. Parameters used in the simulation

\begin{tabular}{|c|c|c|c|}
\hline Parameter & Physical Meaning & Value & References \\
\hline$L_{+}$ & Thickness of positive electrode & $55 \mu \mathrm{m}$ & Assumed \\
\hline$L_{\mathrm{e}}$ & Thickness of separator & $30 \mu \mathrm{m}$ & Assumed \\
\hline$L_{-}$ & Thickness of negative electrode & $55 \mu \mathrm{m}$ & Assumed \\
\hline$C_{\mathrm{dl}}$ & Double-layer capacitance & $0.08 \mathrm{~F} / \mathrm{m}^{2}$ & Measured \\
\hline$S_{\mathrm{d}}$ & Specific surface area for double-layer capacitance per unit electrode volume & $6 \times 10^{8} \mathrm{~m}^{-1}$ & Measured \\
\hline$S_{\mathrm{f}}$ & Specific surface area for side-reactions per unit electrode volume & $0.1 \mathrm{~m}^{-1}$ & Assumed \\
\hline$D_{1}$ & Diffusion coefficient of electrolyte & $4.1 \times 10^{-10} \mathrm{~m}^{2} / \mathrm{s}$ & 18 \\
\hline$\varepsilon_{\mathrm{S}}$ & Volume fraction of solid phase & 0.5 & Assumed \\
\hline$\varepsilon_{1}$ & Volume fraction of electrolyte phase & 0.33 & Assumed \\
\hline$i_{0}$ & Exchange current density & $10 \mathrm{~A} / \mathrm{m}^{2}$ & Assumed \\
\hline$c_{0}$ & Initial concentration of electrolyte & $2 \mathrm{~mol} / \mathrm{L}$ & Measured \\
\hline$T$ & Temperature & $298.15 \mathrm{~K}$ & Assumed \\
\hline$t_{+}$ & Transport number & 0.363 & 17 \\
\hline$\alpha_{\mathrm{a}}$ & Anodic transfer coefficient of faradaic reaction & 0.5 & 19 \\
\hline$\alpha_{c}$ & Cathodic transfer coefficient of faradaic reaction & 0.5 & 19 \\
\hline$\sigma_{\mathrm{s}}$ & Conductivity in solid phase of electrodes & $34.2 \mathrm{~S} / \mathrm{m}$ & Measured \\
\hline$\sigma_{1}$ & Conductivity in electrolyte phase & $0.94 \mathrm{~S} / \mathrm{m}$ & 20 \\
\hline
\end{tabular}

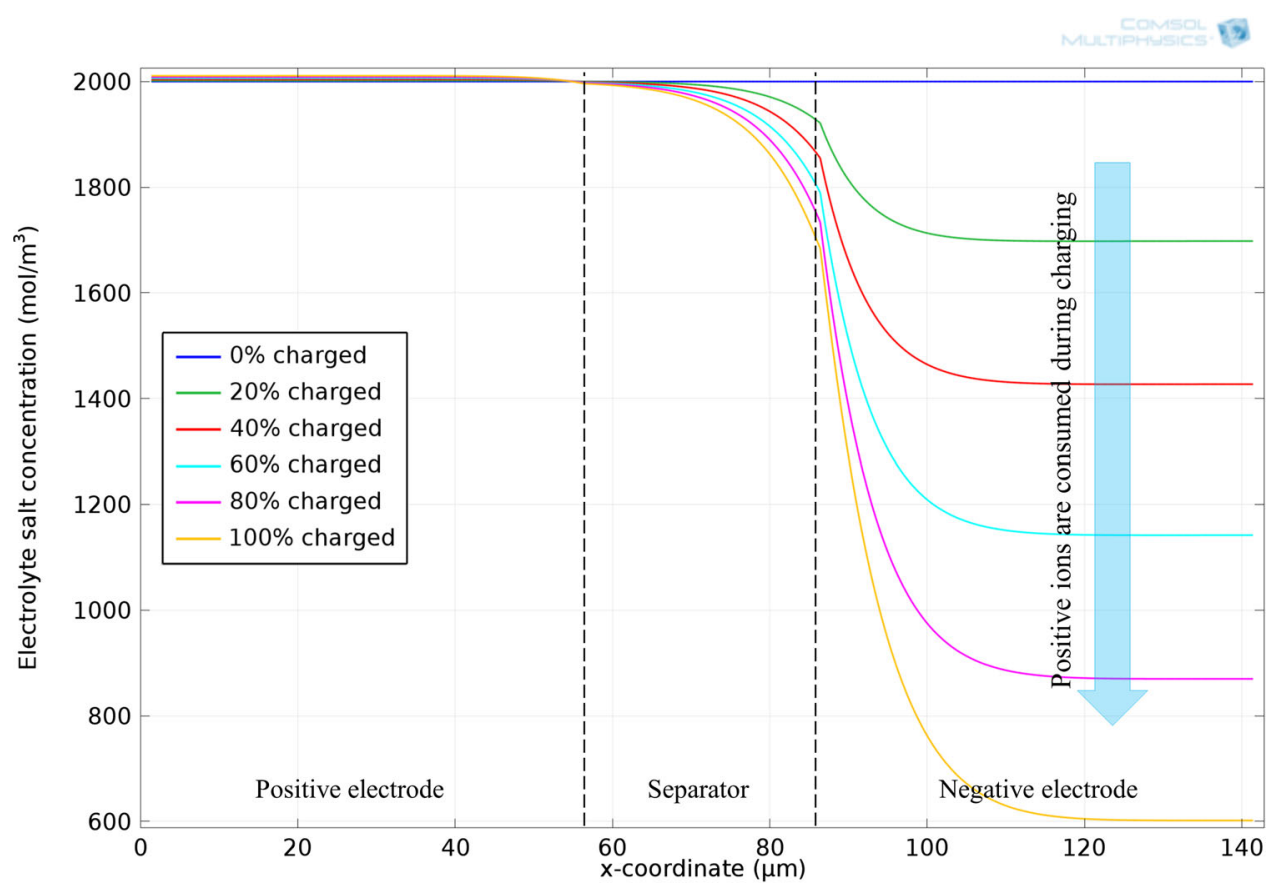

Fig. 6. Concentration gradients of positive ions across the capacitor during the charging process (Color figure online).

layer. The situation in the positive electrode is just the opposite.

As shown in Fig. 7, the first stage of self-discharge is a period of relaxation, powered by the ion concentration gradients. Positive ions transfer from the positive electrode to the negative electrode, and negative ions transfer in the opposite direction. Some of the unstable double layers also lose their ions in the process. In the positive electrode, for example, some negative ions leave the double layer to the electrolyte phase, attracted by the excess positive ions, which is especially pronounced at the head of the electrode. During the process, the supercapacitor quickly loses significant capacity due to the redistribution of ions.

At the end of the first stage, the concentration gradients of ions along the electrolyte are almost eliminated. For ions in the double layer, the attraction from the opposite ions in the electrolyte phase becomes nearly balanced with the binding force of the double layer. The self-discharge then moves into a second stage where ions escape from 


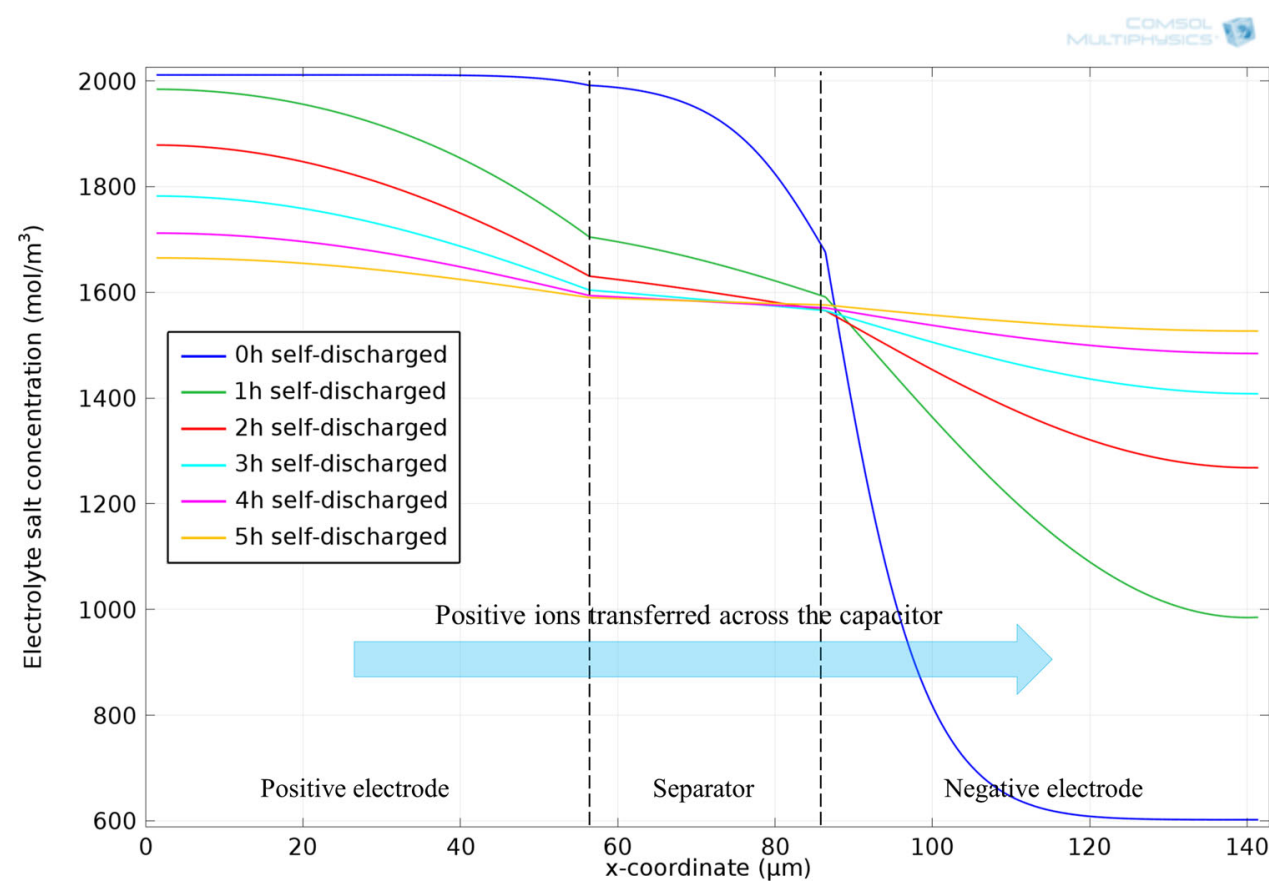

Fig. 7. Concentration gradients of positive ions across the capacitor during the first stage of self-discharge (Color figure online).

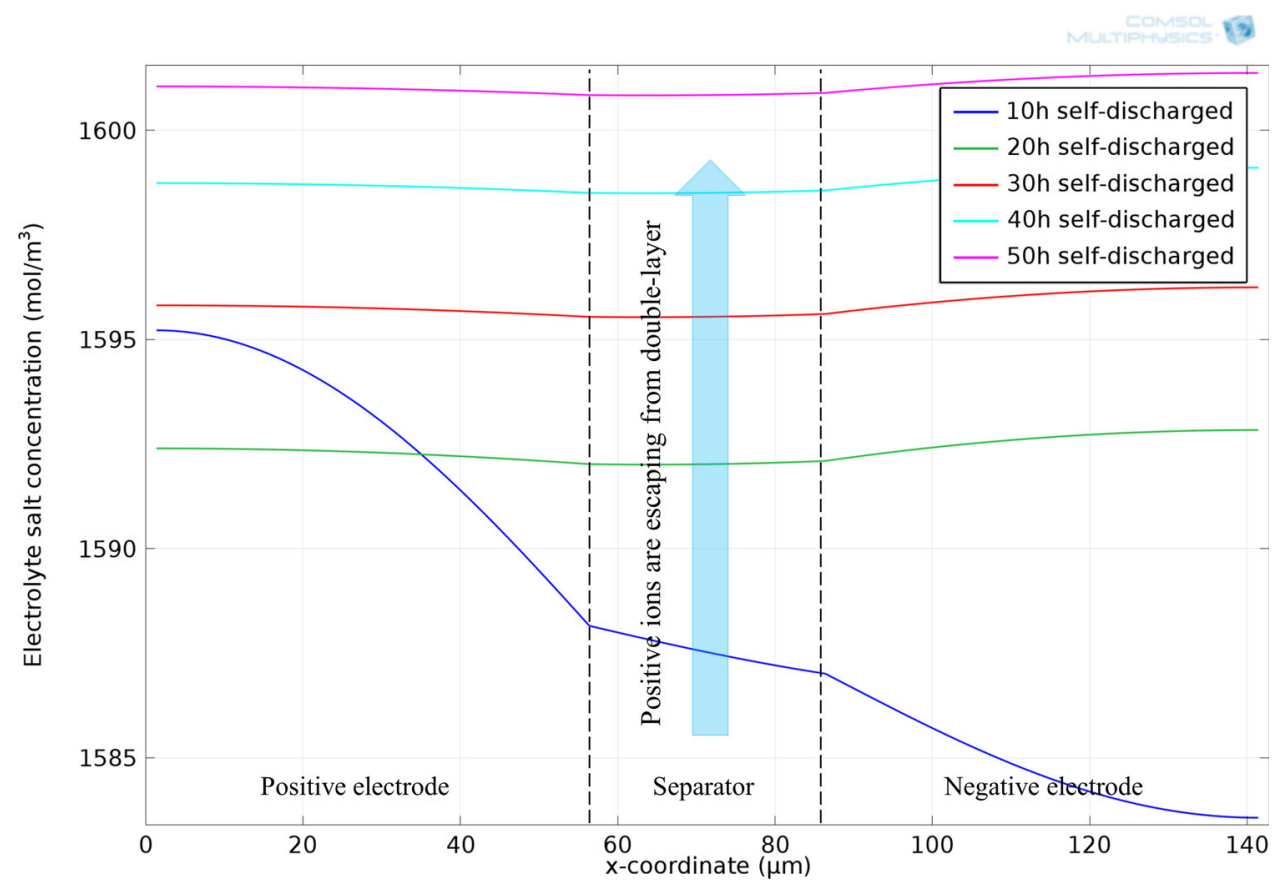

Fig. 8. Concentration gradients of positive ions across the capacitor during the second stage of self-discharge (Color figure online).

the double layers much more slowly. As shown in Fig. 8, there are almost no concentration gradients across the electrolyte after $10 \mathrm{~h}$ of self-discharge. An increasing number of ions begin to escape from the double layer to the electrolyte as time passes, which leads to a slow voltage decay of the supercapacitor.

\section{Effect of Initial Voltage}

The experimental data in Fig. 1 show that the voltage decays faster for higher initial voltage. Figure 9 shows the simulation results compared with the experimental data. According to the simulation and discussion in "Movement of Ions During 


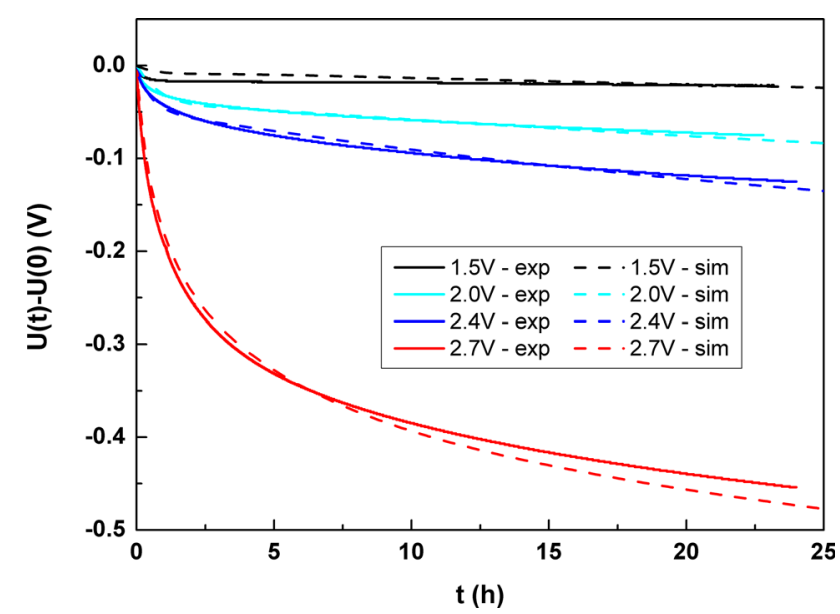

Fig. 9. Simulation results of effect of initial voltage compared with experimental data (Color figure online).

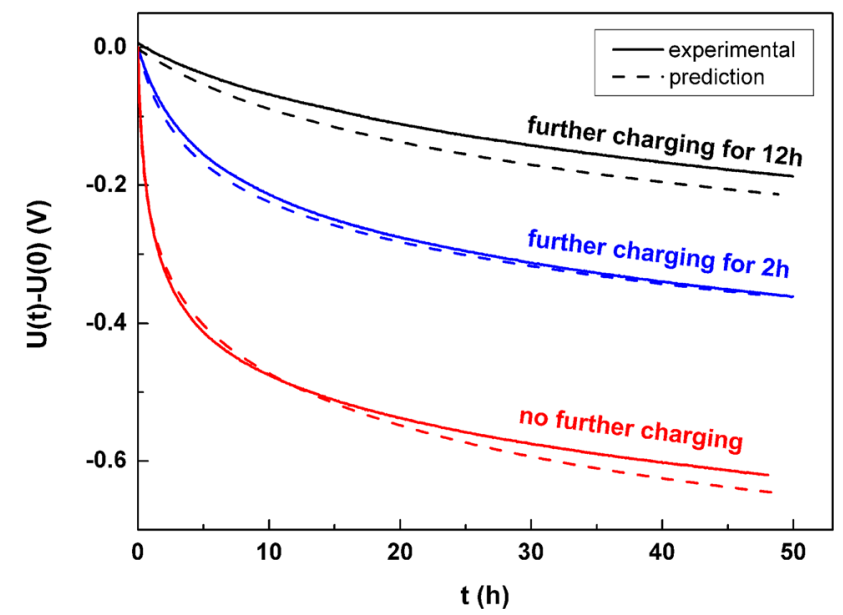

Fig. 10. Simulation results of effect of charge duration compared with experimental data (Color figure online).

the Charge/Self-discharge Process" section, there are three possible reasons for this result. Firstly, the ion distribution is more unbalanced when the supercapacitor is charged to a higher voltage. Thus, more energy is lost in the relaxation period. Secondly, there are more unstable double layers at higher voltage. Thirdly, more side-reactions including impurities and electrolyte decomposition tend to happen when the voltage is higher.

\section{Effect of Charge Duration}

The experimental data are shown in Fig. 2. Figure 10 shows the simulation results based on the mathematical model. It shows that the further charging reduces the rate of self-discharge, especially at the beginning - the relaxation period. After further charging for $12 \mathrm{~h}$, the relaxation process is almost avoided, but the slow voltage decay in the second stage of self-discharge is almost unaffected. As predicted in "Movement of Ions During the

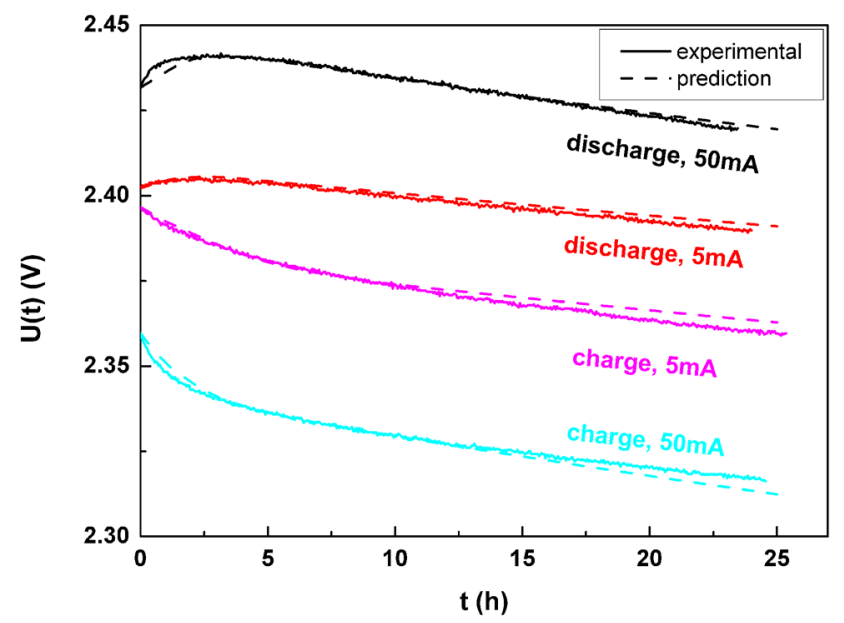

Fig. 11. Simulation results of effect of short-term history and current compared with experimental data (Color figure online).

Charge/Self-discharge Process" section, further charging provides a rest period for ions to move across the electrolyte driven by the unbalanced distribution. After the further charging, the ions would be more equally distributed than before, which eliminates the driving force of the relaxation process. However, it has little effect on the second stage of self-discharge because it cannot change the instability characteristic of the double layers.

\section{Effect of Short-Term History and Current}

The experimental data in Fig. 4 show that a short charging process was followed with voltage decay and a short discharging process was followed with voltage increase. The simulation results are shown in Fig. 11. The short-term history disrupts the distribution balance of ions. After further long-term charging, the ion distribution is balanced. However, short discharging leads to another unbalanced distribution of ions. Then, just as the short discharge ends, the redistribution effect drives some ions back to the double layer. At the same time, the voltage recovers, leading to a small voltage increase. For the same reason, short charging results in a small voltage drop. Moreover, the experimental data and simulation results show the important role of current. The charging/discharging current has seldom been discussed in related studies, but it plays a decisive role in the relaxation period. When a small current is applied in the short-term history, the voltage variations in the relaxation period are reduced, as shown in Fig. 11. This proves that a larger current would magnify the effect of shortterm charging/discharging, whereas a small current would eliminate the effect of the short-term history. A reasonable interpretation is that, when a small current is applied, the reactions on the electrode become much slower. In this case, the movement of ions could almost catch up with the production and consumption of ions. Therefore, there are not large 

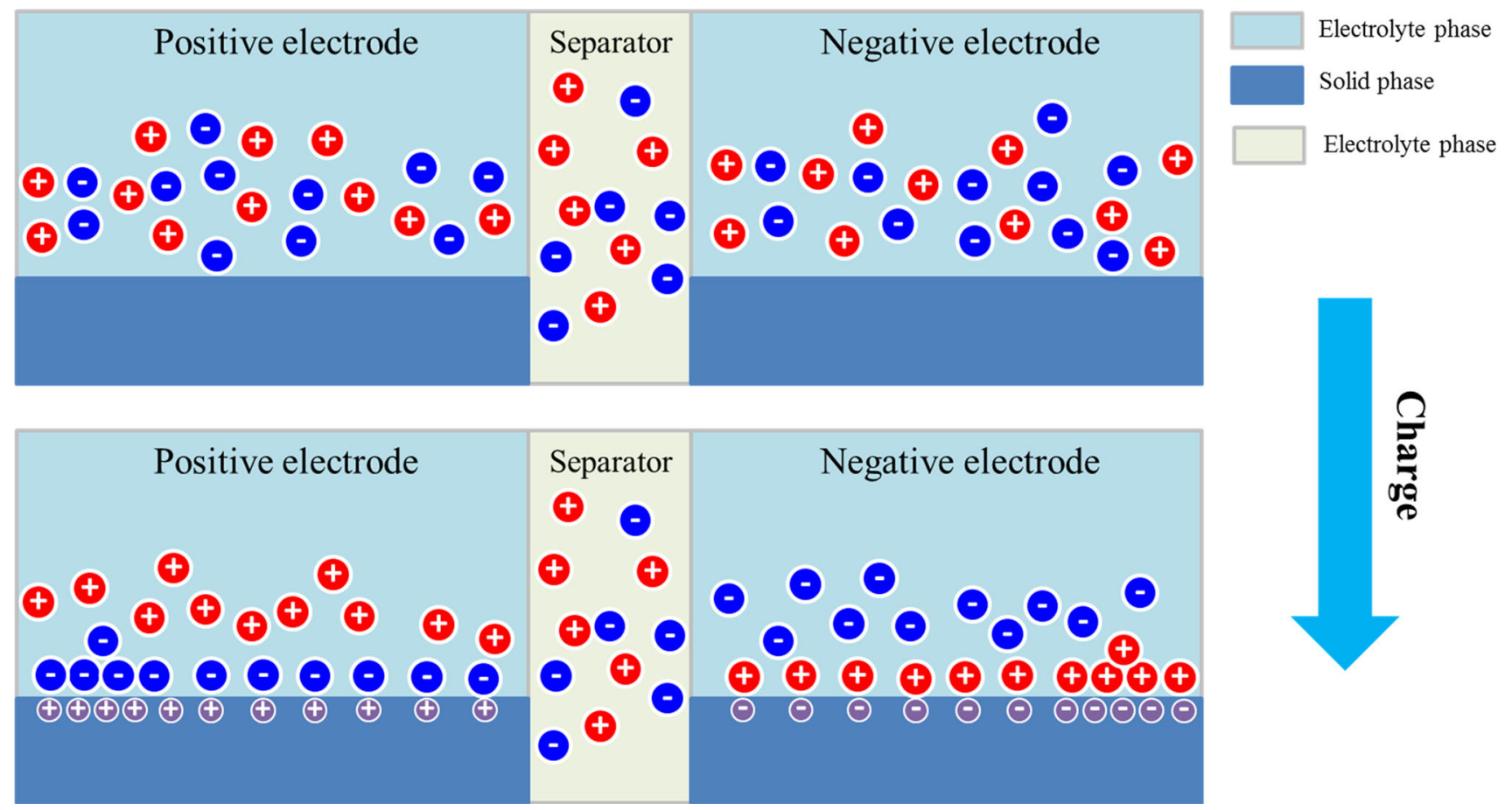

Fig. 12. Schematic of ion distribution during the charging process (Color figure online).

distribution gradients across the electrolyte in the short-term charging/discharging process. The relaxation period would then not take place in the selfdischarge.

\section{Mechanism of Self-discharge}

This section summarizes the mechanism of selfdischarge presented in the former sections. According to the simulation results, a normal self-discharge has two stages: a fast diffusion stage and a slower voltage decay stage. The redistribution effect due to concentration gradients of ions is the main cause of the first stage. Side-reactions and the instability of double layers contribute to the selfdischarge in both stages.

Figure 12 displays a schematic of the ion distribution during the charging process. Initially, positive and negative ions distribute evenly across the electrolyte. As soon as a current flows into the supercapacitor, negative ions begin to be absorbed in the positive electrode, and positive ions begin to be absorbed in the negative electrode, which forms double layers at the interfaces between the solid phase and the electrolyte phase inside the electrodes. However, the reaction rate is different across the electrode, resulting in the formation of concentration gradients. At the end of charging, the ions across the electrolyte and the charges across the electrode are unevenly distributed. The uneven distribution of ions causes two types of driving forces: one drives ions to transfer across the electrolyte, and the other drives charges to escape from the double layer. In the positive electrode, for instance, negative ions are absorbed to the double layers, and there are more positive ions left in the electrolyte phase. Therefore, under the driving forces, positive ions transfer from the positive electrode to the negative electrode. Negative charges in the double layer, attracted by the positive ions left in the electrolyte, likely escape back to the electrolyte phase. However, due to the uneven distribution of double layers across the electrode, areas where the double layer is concentrated are more likely to lose their charges.

Figure 13 shows a schematic of the self-discharge process. It is divided into two stages. The driving forces caused by the uneven ion distribution bring about the first stage of self-discharge-relaxation. The relaxation is a fast diffusion process where ions move across the electrolyte and charges escape from the double layers, motivated by the driving forces. Therefore, the capacitor suffers a rapid and profound loss of energy in relaxation. This process takes a few hours, and a relative equilibrium is eventually reached. All ions and charges are equally distributed. In the positive electrode, there are fewer positive ions left in the electrolyte phase. Therefore, the driving force exerted on charges to escape from the double layer is much smaller. Sidereactions also become less active under a lower voltage. Without the strong driving forces, only a slow voltage decay is observed in the voltage curve of the second stage of self-discharge.

However, if the supercapacitor is further charged at the end of the charging process, the situation is different, as shown in Fig. 14. When the 

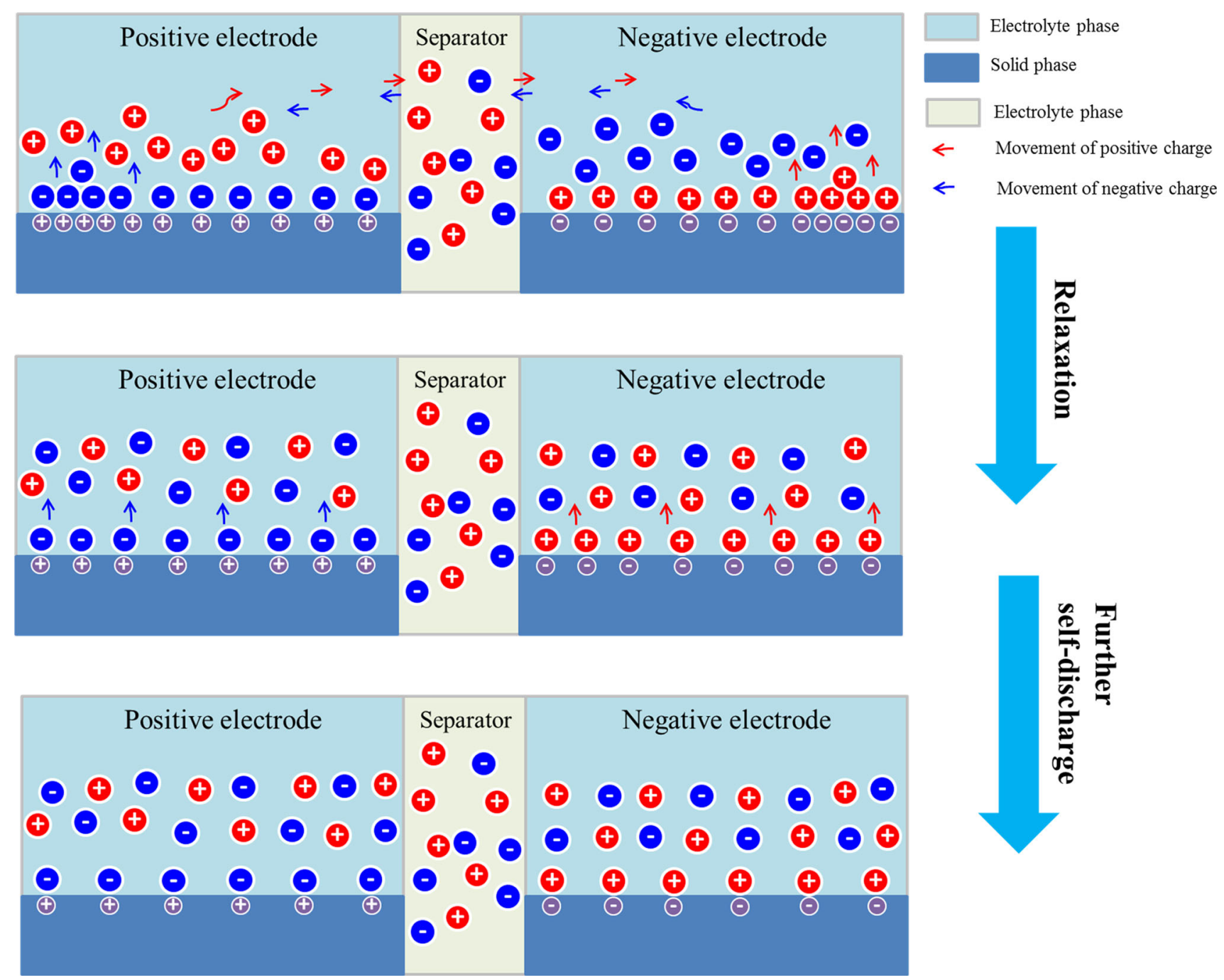

Fig. 13. Schematic of ion distribution during the self-discharge process (Color figure online).

supercapacitor is further charged after reaching the target voltage, the ions transfer to eliminate the concentration gradient, just like in the relaxation stage of the self-discharge. However, the difference is that the lost double layers and reduced capacity are recovered in the further discharge. Finally, the double layer across the electrode is in a state of homogeneous distribution. Eliminating the unbalanced distribution during the further discharge process causes the capacitor to skip the relaxation stage of self-discharge, being an important characteristic of the further discharge.

With a further charging process, the capacitor reaches a comparative equilibrium in which no fast diffusion process occurs. However, a short charging process or discharging process breaks the equilibrium. A short charging process causes unequal ion distributions, as stated above. However, the extent of the imbalance is smaller because the charging takes less time. Therefore, the short charging process is followed by a small voltage decay. A short discharging process, however, acts in the opposite way. During discharging, charges escape from double layers and move back to the electrolyte, the rate of which is much faster than self-discharge. Therefore, unlike self-discharge, the transfer of ions cannot catch up with the reaction rate, causing an unbalanced ion distribution. Once the discharging is stopped, the unbalanced ion distribution drives ion transfer across the electrolyte and pushes some ions back to re-form the double layer. This explains the voltage recovery phenomenon during the relaxation period. After the relaxation period ends, a new equilibrium is reached, followed by slow voltage decay.

An important factor neglected by former research is the charging or discharging current, as shown in Figs. 3 and 11. During charging, for example, a larger current increases the reaction rate. Double layers form more quickly, and concentration gradients across the capacitor become larger. The larger the concentration gradient, the more time it takes 

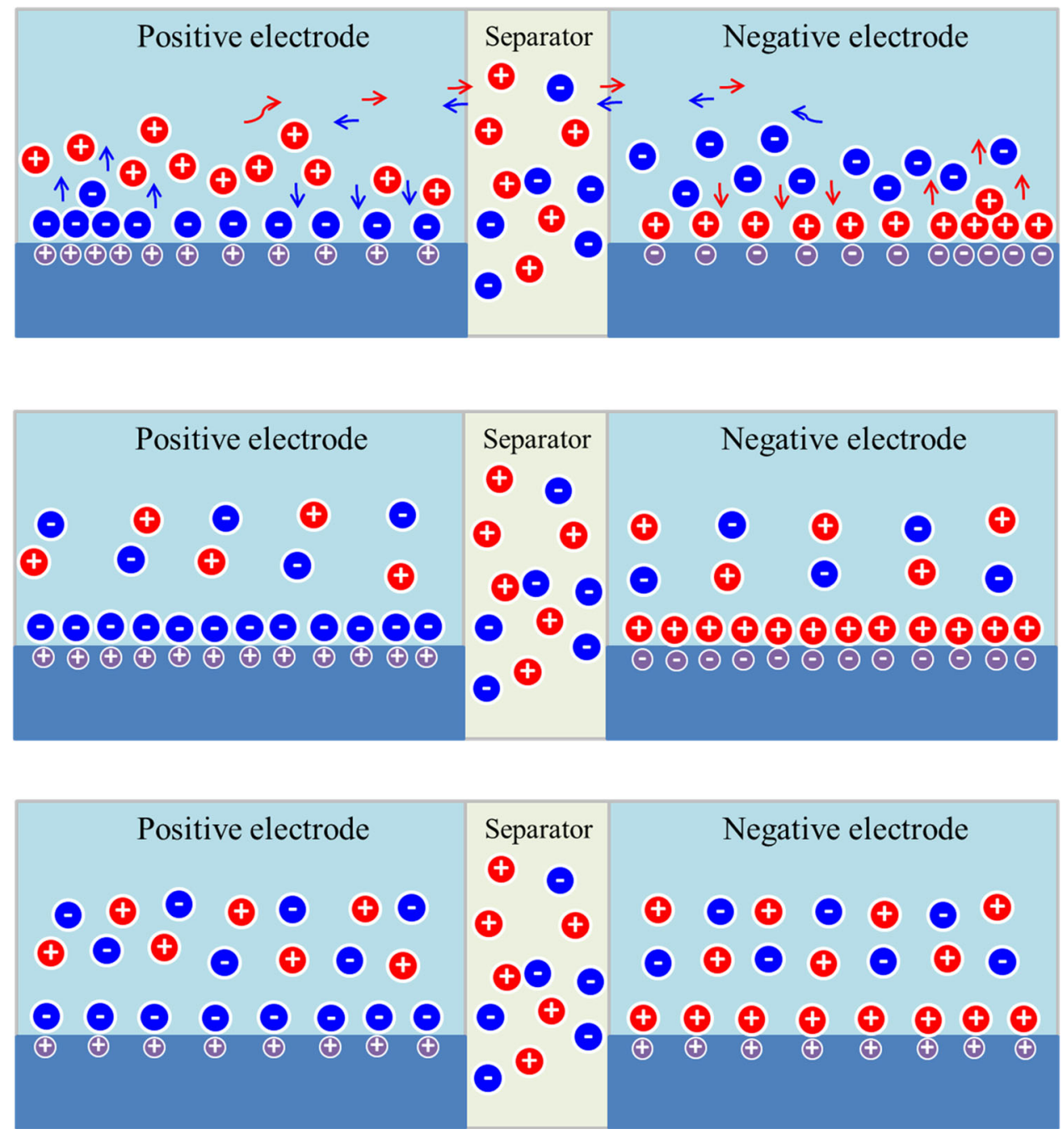
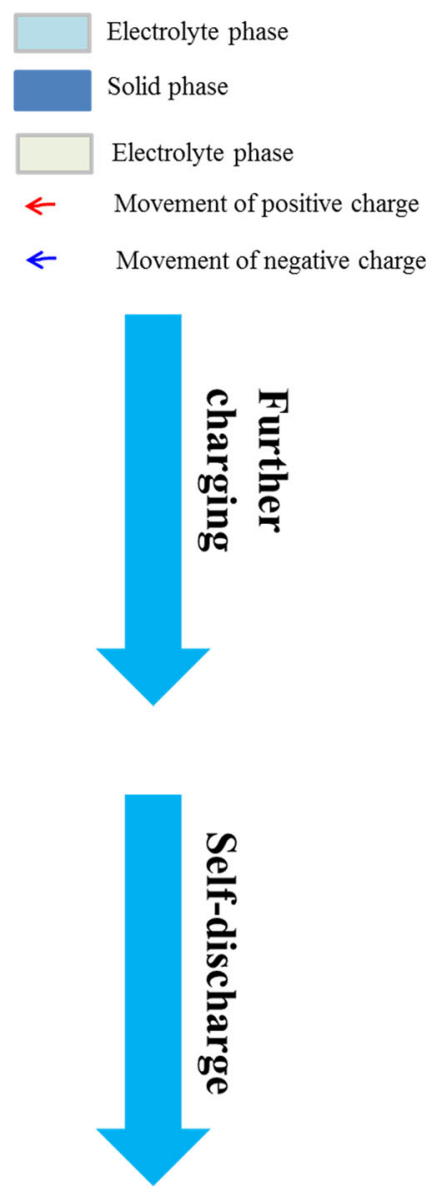

Fig. 14. Schematic of ion distribution with a further charging process (Color figure online).

for redistribution of ions, and the more energy is lost in the charge redistribution. On the contrary, if the charging current is small enough, the reaction rate is small and the diffusion rate of ions can catch up with it. Then, the concentration gradients are small enough to be ignored. In this case, the charge redistribution does not happen, even without a further charging process. In other words, applying a small charging current plays the same role as a further charging process, as shown in Fig. 15. This makes the effect of the short-term history clearer. If the charging/discharging current is small, then the short charging/discharging to $2.4 \mathrm{~V}$ does not make too much difference, as shown in Fig. 11.

\section{CONCLUSIONS}

We propose a mathematical model to describe the self-discharge behavior of double-layer supercapacitors. The movement of ions, side-reactions, and the instability of the double layer are taken into consideration. Many factors, including the initial voltage, charge duration, short-term history, and current, that influence self-discharge are simulated. The results agree well with experimental data. The simulation also gives a detailed explanation of the mechanism of self-discharge and verifies the charge redistribution interpretation proposed in a recent study ${ }^{9}$ based on theoretical calculations. The results show that self-discharge has two distinct stages: a fast diffusion stage and a slow voltage decay stage. The fast diffusion stage, during which the supercapacitor loses energy very quickly, is due to the redistribution effect of the concentration gradients, and it could be avoided by further charging or applying a small current. In fact, the large current is responsible for the unbalanced distribution of ions because the transfer of ions across the electrolyte cannot catch up with the reaction rate. 

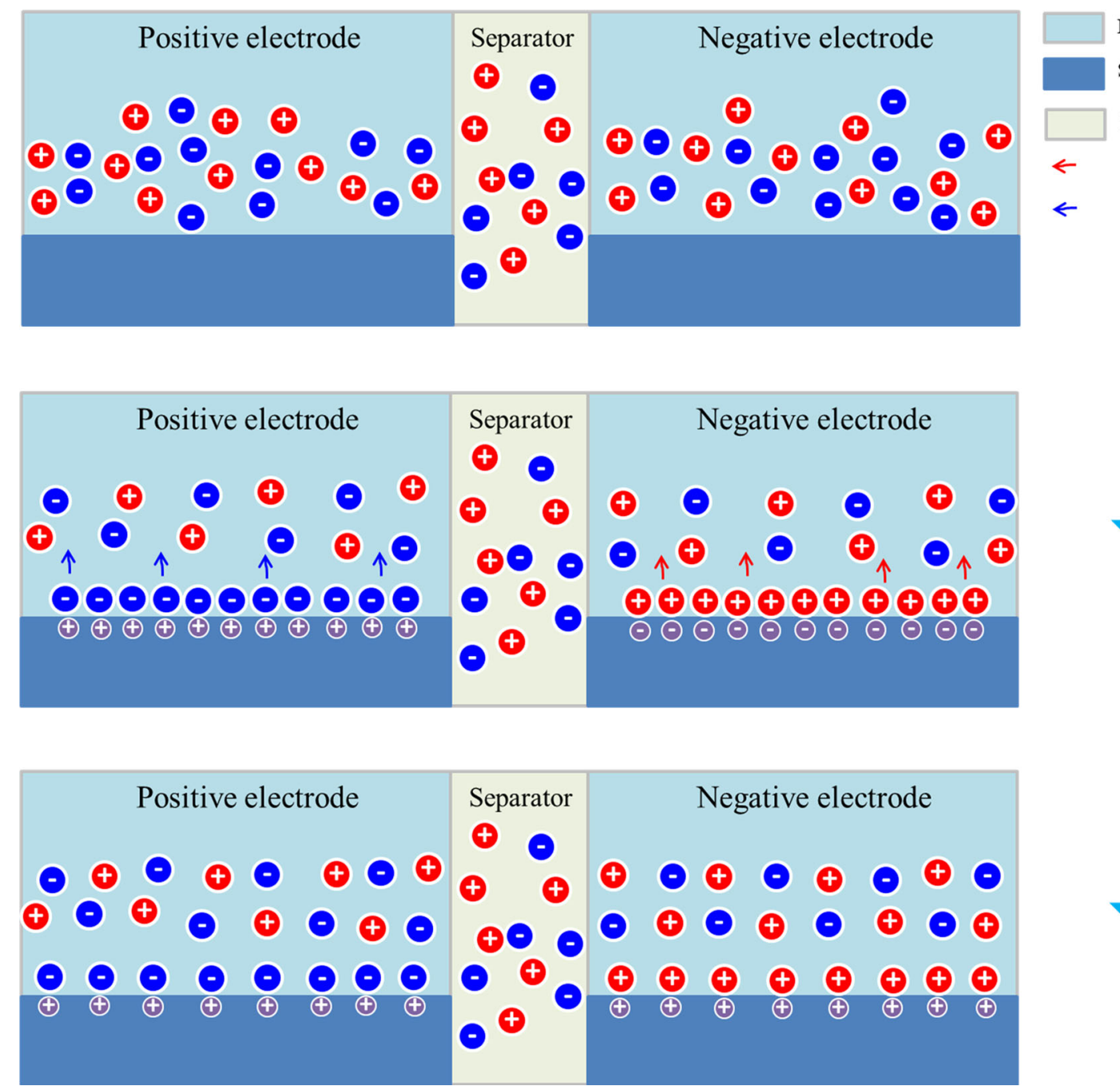

Electrolyte phase

Solid phase

Electrolyte phase

Movement of positive charge

Movement of negative charge

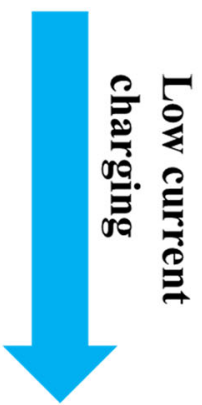

Fig. 15. Schematic of ion distribution when a low charging current is applied (Color figure online).

\section{ACKNOWLEDGEMENT}

The authors acknowledge financial support from the National Natural Science Foundation of China (NNSFC) (Project No. 50905096).

\section{CONFLICT OF INTEREST}

The authors declare that they have no conflict of interest.

\section{REFERENCES}

1. R. Kötz and M. Carlen, Electrochim. Acta 45, 2483 (2000).

2. A. Burke, J. Power Sources 91, 37 (2000).

3. A. Balducci, W.A. Henderson, M. Mastragostino, S. Passerini, P. Simon, and F. Soavi, Electrochim. Acta 50, 2233 (2005).

4. T. Zhu, Z. Zhong, Y. Gu, T. He, and Z.L. Zhang, Proceedings of the 7th international conference on Mobile systems, applications, and services. ACM, Vol. 319 (2009).

5. B.E. Conway, W.G. Pell, and T.C. Liu, J. Power Sources 65, 53 (1997).

6. R.D. Levie, Electrochim. Acta 8, 751 (1963).

7. B.W. Ricketts and C. Ton-That, J. Power Sources 89, 64 (2000).
8. J. Black and H.A. Andreas, Electrochim. Acta 54, 3568 (2009).

9. J. Kowal, E. Avaroglu, F. Chamekh, A. Senfelds, T. Thien, D. Wijaya, and D.U. Sauer, J. Power Sources 196, 573 (2011).

10. M. Kaus, J. Kowal, and D.U. Sauer, Electrochim. Acta 55, 7516 (2010).

11. F.A. Posey and T. Morozumi, J. Electrochem. Soc. 113, 176 (1966).

12. A.M. Johnson and J. Newman, J. Electrochem. Soc. 118, 510 (1971).

13. B. Pillay and J. Newman, J. Electrochem. Soc. 143, 1806 (1996).

14. V. Srinivasan and J.W. Weidner, J. Electrochem. Soc. 146, 1650 (1999)

15. C. Hao, X. Wang, Y. Yin, and Z. You, J. Electron. Mater. 45, 515 (2016).

16. J. Newman and K.E. Thomas-Alyea, Electrochemical Systems, 3rd ed. (Hoboken: Wiley, 2004), pp. 297-315-518526.

17. J. Newman and W. Tiedemann, AIChE J. 21, 25 (1975).

18. A. Nyman, M. Behm, and G. Lindbergh, Electrochim. Acta 53, 6356 (2008).

19. C. Lin, J.A. Ritter, B.N. Popov, and R.E. White, J. Electrochem. Soc. 146, 3168 (1999).

20. M. Ue, M. Takeda, M. Takehara, and S. Mori, J. Electrochem. Soc. 144, 2684 (1996). 